\title{
Typical MRI Features in Spontaneous Intracranial Hypotension: A Rare Cause of Headache
}

\author{
N Hekha, CC Tchoyoson Lim
}

Department of Neuroradiology, National Neuroscience Institute, Duke-NUS Graduate Medical School, Singapore

\begin{abstract}
Spontaneous CSF leakage from the spinal canal can give rise to spontaneous intracranial hypotension $(\mathrm{SIH})$. Typically, these patients complain of orthostatic (postural) headache, have very low CSF pressure on lumbar puncture (LP) and usually respond to conservative treatment or by an epidural blood patch. The characteristic MRI features include subdural fluid collections, enhancement of the pachymeninges, engorgement of venous structures, pituitary hyperaemia and sagging of the cerebellar tonsils. Radiologists should recognize the typical clinical and imaging features of SIH and distinguish it from more sinister or malignant differential diagnosis, in order to prevent a delay in diagnosis or unnecessary surgical intervention, especially in resource-constrained situations in developing nations.
\end{abstract}

Key words: MRI, SIH, Lumbar Puncture, CSF

\section{Introduction}

CT or MRI investigation for a patient presenting with headache is one of the commonest indications radiologists come across in daily clinical practice. Although many of these studies are normal, there lurk important sinister diagnosis such as ruptured aneurysm, neoplasm, meningitis and cerebral venous thrombosis, for which we should be on the alert ${ }^{1,2}$. On the other hand, there are several rare, but characteristic benign conditions, including spontaneous intracranial hypotension $(\mathrm{SIH})$ caused by spinal cerebrospinal fluid leak, that should also be recognized as such by radiologists ${ }^{3-}$ ${ }^{10}$. We present a case of SIH and illustrate the typical MRI features radiologists should be familiar with.

Correspondence to: Dr CC Tchoyoson Lim Department of Neuroradiology, National Neuroscience Institute, Duke-NUS Graduate Medical School, Singapore

Email: Tchoyoson_Lim@nni.com.sg

\section{Case Report}

A 41 year old woman complained of gradual worsening of headache over a period of 2 weeks. The pain was described as a 'dragging' sensation, most severe at the occipital region. It worsened on standing up and improved when she was in a recumbent position. She became progressively bedbound, being only able to sit up for short periods before she had to lie down again. Physical examination revealed no abnormality and lumbar puncture (LP) showed low opening pressure that was unrecordable. CSF examination was normal, CT brain study was unremarkable and the patient proceeded to contrast-enhanced MRI. On T2-weighted images, there were small, bilaterally symmetrical small hyperintense fluid collections (arrows in Fig 1), which were located in the cerebral and cerebellar subdural spaces and were also hyper intense on FLAIR images (arrows in Fig 2). After contrast media injection, there was diffuse and uniform intense enhancement of all the dural surfaces, including the falx and 


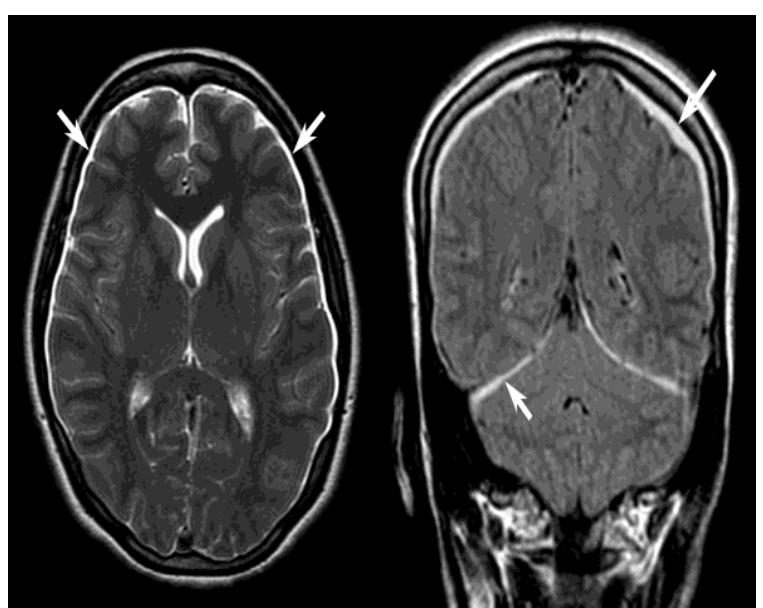

Figs 1 \& 2: T2-weighted and FLAIR images show bilaterally symmetrical, thin, hyperintense, subdural fluid collections (arrows).

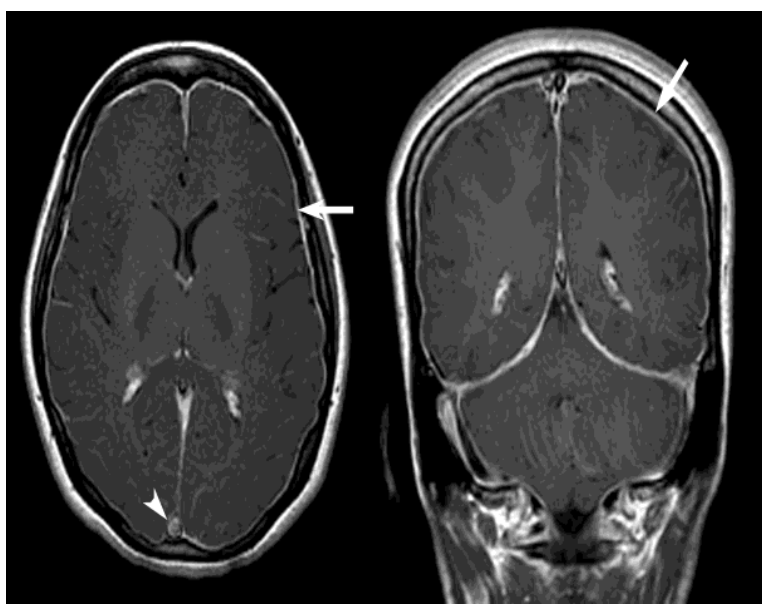

Figs 3 \& 4: Diffuse dural enhancement (arrows) is seen on axial and coronal contrast-enhanced T1-weighted images. Additionally, there is venous engorgement of the superior sagittal sinus (arrowhead).

tentorium (arrows in Fig 3 to 5). The thickened and enhancing dura showed a smooth, non-nodular pattern. In addition, there was venous engorgement of the superior sagittal and transverse sinuses (arrowhead in Fig 3) and prominent hyperaemic enhancement of the pituitary gland (arrowhead in Fig 5). The brain was sagging, with inferiorly displaced cerebellar tonsils and decreased pre-pontine CSF space.

The diagnosis of SIH was made on the basis of typical headache symptoms, low CSF pressure and characteristic MRI findings The patient was treated conservatively with bed rest, oral hydration and increased caffeine intake. She gradually improved and was discharged after $\mathrm{xx}$ days in hospital; she declined further imaging and treatment. At the last follow up after $\mathrm{xx}$ months the headaches had since then not recurred.

\section{Discussion}

This patient illustrates the typical MRI features of SIH, including subdural fluid collections, enhancement of the pachymeninges, engorgement of venous structures, pituitary hyperemia and sagging of the brain. These findings may be summarized in the convenient mnemonic SEEPS ${ }^{3}$, which allow confident diagnosis without having to resort to invasive procedures, such as LP or intracranial pressure monitoring ${ }^{3-5}$.

\section{Pathogenesis and epidemiology of SIH}

The primary cause of SIH is an occult spontaneous CSF leak from the spinal canal. According to the Monroe-Kellie hypothesis, the sum of the volumes of cerebral tissue, intracranial blood and CSF is constant in an intact cranium. Hence, any CSF leak must be compensated by venous engorgement (not arterial as this is tightly auto regulated) or increase in the subdural space ${ }^{3-6}$.

Initially thought to be rare, SIH cases came to attention in the $90 \mathrm{~s}$ due to more widespread use of MRI; the incidence has been estimated at 5 per 100000 per year 3, 68. Synonyms for SIH in the literature include intracranial hypotension, CSF leak, low pressure headache and CSF hypovolemia. Women are affected more commonly (nearly 2:1) and the peak incidence is around the age of 40 years, with associations including connective tissue disease, trivial traumatic event (one third of patients) ${ }^{9,10}$ and acquired degenerative disk disease ${ }^{11,12}$. Connective tissue disorders that may be associated 


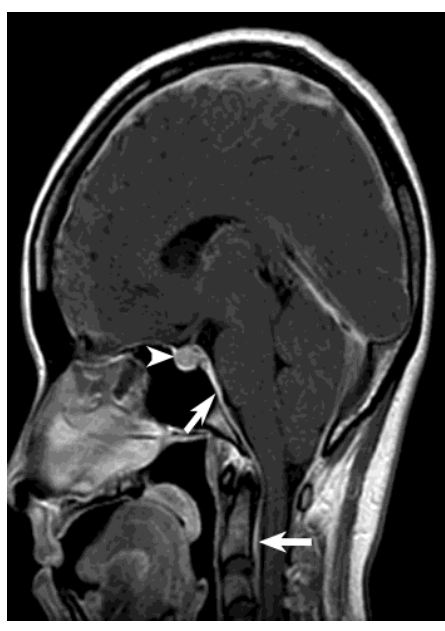

Fig 5: A

sagittal contrast

- enhanced T1-

weighted image

shows

prominent

enhancement of

the pituitary

gland

(arrowhead), sagging of the

brain with

inferiorly

displaced cerebellar tonsils and reduction

of the pre-pontine CSF space. The dural

enhancement (arrows) extends into the spinal canal.

include Marfan syndrome, Ehlers-Danlos syndrome and autosomal dominant polycystic kidney disease ${ }^{13-15}$; SIH patients without overt syndromes may also show subtle manifestations of isolated joint hypermobility ${ }^{16}$.

\section{MRI features of SIH}

The MRI findings represent the sum of loss of CSF volume (and buoyancy) and compensatory changes in response to the leakage. Thin, bilateral, subdural fluid accumulation over the cerebral and cerebellar convexities is commonly seen in about $50 \%$ of patients ${ }^{17-19}$. They typically do not cause mass effect and represent small hygromas. Occasionally, subdural haemorrhage can be seen.

The pachymeningeal (dural) enhancement is bilateral, diffuse, involves both supratentorial and infratentorial compartments and spares the leptomeninges ${ }^{6}$. This common (in $80 \%$ of cases) ${ }^{20,21}$ and striking appearance has been likened to a "felt tip pen" outlining the thickened, enhancing dura in a diffuse and non-nodular pattern. It is thought to be caused by engorgement of the small, thinwalled dilated blood vessels in the subdural zone $^{22}$.
Dural venous sinus engorgement 23,24 and Pituitary hyperaemia or enlargement ${ }^{25,26}$ are also due to compensatory increase in the venous blood component to balance the loss in cranial volume and pressure, but are less constant and less striking signs of SIH. These are often only appreciated on comparison with post-treatment, normalized venous structures.

Sagging and downward displacement of the cerebellar tonsils or effacement of prepontine cistern with flattening of the pons against the clivus $^{6}$ may mimic a Chiari type 1 malformation or it can be misdiagnosed as increased intracranial pressure from sinister cause such as space-occupying lesions.

\section{Clinical presentation}

Orthostatic headache is the prototypical symptom, with occipital or sub-occipital pain occurring or worsening within minutes of assuming the upright position and improvement on resuming recumbency. This classic positional headache is due to downward displacement of the brain due to CSF loss or due to the pain-sensitive dura in the presence of compensatory dilation of venous structures.

Not all patients who have SIH have orthostatic headache and not all patients with postural headache have SIH. In some patients, the postural component may be absent or they may have "thunderclap" headache that might result in unnecessary invasive testing for subarachnoid hemorrhage $^{14}$. Other clinical signs and symptoms that have been documented in SIH include nausea, vomiting, diplopia with visual disturbance, cranial nerve palsies and even encephalopathy and coma. Atypical features are not uncommon and these other associated symptoms might manifest differently from "textbook" cases of SIH.

\section{Further Radiological investigations}

CT myelography of the entire spine after 
iodinated contrast is the study of choice to accurately define the location and extent of a CSF leak or the presence of meningeal diverticula, typically in the cervicothoracic junction or thoracic spine ${ }^{14}$. Radionuclide cisternography and spinal MRI are alternative methods to delineate the CSF leak, but may have limited sensitivity $3,14,27$, 28 .

\section{Management of SIH}

However, many patients do not proceed to these more invasive investigations and in patients with classical orthostatic headache and typical MRI features, confirmation of low pressure by LP may not even be necessary. Most cases of SIH resolve with conservative treatment including bed rest, oral hydration, and caffeine. A trial of therapeutic epidural blood patch has been advocated as the next management step if conservative management is unsuccessful and symptoms persist. This involves empirical replacement of lost CSF volume with an autologous blood volume (20-100 $\mathrm{mL}$ ) into the epidural space of the spinal canal to tamponade and seal any leaks ${ }^{29,30}$. Although none of the treatments have been evaluated by randomized clinical trials, blood patch is usually successful and CT myelography to isolate the site of leakage is usually reserved for patients who have failed a trial of epidural blood patch and in preparation for definitive surgical treatment ${ }^{3}$,

Most patients show improvement within days to weeks of successful blood patch treatment, with MRI abnormalities lagging behind clinical improvement; subdural hematomas may take months to resolve. However, if there is recurrence of headache due to recurrent CSF leak $^{31}$ or if the pattern of headache has changed, rebound transient intracranial hypertension ${ }^{14}$ or dural venous sinus thrombosis should be considered ${ }^{32-34}$.

\section{Differential Diagnosis}

The differential diagnosis for headache is wide, with many patients being referred for neuroimaging; many (typically without suspicious "red flags" symptoms) will have normal findings on conventional CT or MRI, and these form a majority of daily clinical practice. Nevertheless, radiologists should be alert to the sinister causes of headache that may be visible on imaging, including subarachnoid haemorrhage, meningitis or encephalitis, space occupying lesions such as neoplasm, arterial dissection and cerebral venous thrombosis ${ }^{35}$.

The differential diagnosis of the MRI findings in SIH is important to consider: in particular idiopathic hypertrophic pachymenigitis which can present with diffuse dural enhancement. Pachymeningeal enhancement may be seen in metastatic malignant tumor deposits, but these tend to be multifocal and nodular rather than diffuse $^{36}$. Infectious meningitis typically affects the leptomeninges rather than pachymeninges, and the leptomeningial enhancement pattern is different; however, some infectious agents, especially tuberculosis, can cause pachymeningitis as well as leptomeningitis ${ }^{37}$.

CSF loss and low intracranial pressure not caused by spontaneous leakage, but by acquired causes can also demonstrate dural enhancement, including scans performed shortly after intracranial surgery or in the presence of ventricular shunts. Post-LP headache syndrome has similar MRI features of dural enhancement, and can be a very difficult clinical conundrum as LP is commonly carried out to diagnose meningitis 3,9

\section{Conclusion}

Although there are typical clinical and MRI features such as postural headache, subdural fluid collections, enhancement of the pachymeninges, engorgement of venous structures, pituitary hyperaemia and sagging 
of the cerebellar tonsils, sometimes the wide variation of clinical manifestations and unfamiliarity of such a condition among the radiologists may result in a delay in the diagnosis of SIH. It is just as important to minimize false positive diagnosis (overcalling pathology when there is none, or misdiagnosing a benign condition for a malignant disease) as it is to minimize false negative diagnosis (missing a sinister headache cause). Knowledge of the typical MRI findings can help radiologists confidently diagnose the rare but characteristic syndrome of $\mathrm{SIH}$, and avoid unnecessary investigations and surgical procedures, especially in resourceconstrained developing nations.

\section{References}

1. Sobri M, Lamont AC, Alias NA, Win MN. Red flags in patients presenting with headache: Clinical indications for neuroimaging. $\quad \mathrm{Br} \quad J$ Radiol. 2003 Aug;76(908):532-535.

2. Tan AKY, Yeow YK. Warning symptoms of sinister headache. Singapore Med J 1994;35:294-297.

3. Schievink WI. Spontaneous spinal cerebrospinal fluid leaks and intracranial hypotension. JAMA.

2006 May;295(19):2286-2296.

4. Mokri B. Spontaneous cerebrospinal fluid leaks: from intracranial hypotension to cerebrospinal fluid hypovolemiaevolution of a concept. Mayo Clin Proc. 1999;74:1113-1123.

5. Headache Classification Subcommittee of the International Headache Society. The International Classification of Headache Disorders.

6. Fishman RA, Dillon WP. Dural enhancement and cerebral displacement secondary to intracranial hypotension. Neurology. 1993;43:609-611.
7. Schaltenbrand G. Neuere Anschauungen zur Pathophysiologie der Liquorzirkulation. Zentralbl Neurochir. 1938;3:290-300.

8. Mokri B, Krueger BR, Miller GM, et al. Meningeal gadolinium enhancement in low pressure headaches [abstract]. Ann. Neurol. 1991;30:294-295.

9. Nosik WA. Intracranial hypotension secondary to lumbar nerve sleeve tear. JAMA. 1955;157:1110-1111.

10.Schievink WI. Spontaneous spinal cerebrospinal fluid leaks. Neurosurg Focus. 2000;9:1-9.

11.Winter SC, Maartens NF, Anslow P, et al. Spontaneous intracranial hypotension due to thoracic disc herniation: Case report. $J$ Neurosurg. 2002;96:343-345.

12.Rapport RL, Hillier D, Scearce T, et al Spontaneous intracranial hypotension from intradural thoracic disc herniation: case report. J Neurosurg. 2003;98:282284.

13.Schievink WI, Reimer R, Folger WN. Surgical treatment of spontaneous intracranial hypotension associated with a spinal arachnoid diverticulum: case report. J Neurosurg. 1994;80:736-739.

14.Schievink WI, Meyer FB, Atkinson JLD, et al. Spontaneous spinal cerebrospinal fluid leaks and intracranial hypotension. $J$ Neurosurg. 1996;84:598-605.

15.Mokri B, Maher CO, Sencakova D. Spontaneous CSF leaks: underlying disorder of connective tissue. Neurology. 2002;58:814-816.

16.Schievink WI, Gordon OK, Tourje J. Connective tissue disorders with spontaneous spinal cerebrospinal fluid leaks and intracranial hypotension: a 
prospective study. Neurosurgery. 2004;54:65-70.

17.Holmes JM. Intracranial hypotension associated with subdural haematoma. BMJ. 1953;20:1363-1366.

18.Sipe JC, Zyroff J, Waltz TA. Primary intracranial hypotension and bilateral isodense subdural hematomas. Neurology. 1981;31:334-337.

19.Pannullo SC, Reich JB, Krol G, et al. MRI changes in intracranial hypotension. Neurology. 1993;43:919-926.

20.Schievink WI, Tourje J. Intracranial hypotension without meningeal enhancement on magnetic resonance imaging: case report. $J$ Neurosurg. 2000;92:475-477.

21.Schoffer KL, Benstead TJ, Grant I. Spontaneous intracranial hypotension in the absence of magnetic resonance imaging abnormalities. Can J Neurol Sci. 2002;29:253-257.

22.Mokri B, Piepgras DG, Miller GM. Syndrome of orthostatic headaches and diffuse pachymeningeal gadolinium enhancement. Mayo Clin Proc. 1997;72: 400-413.

23.Koss SA, Ulmer JL, Hacein-Bey L. Angiographic features of spontaneous intracranial hypotension. AJNR Am $J$ Neuroradiol. 2003;24:704-706.

24.Roll JD, Larson TC III, Soriano MM. Cerebral angiographic findings of spontaneous intracranial hypotension. AJNR Am J Neuroradiol. 2003;24:707708.

25.Mamelak AN, Fishman RA, Dillon WP, et al. Spontaneous intracranial hypotension. J Neurosurg. 1996;85:192193.
26.Mokri B, Atkinson JLD. False pituitary tumor in CSF leaks. Neurology. 2000;55:573-575.

27.Weber WE, Heidendal GA, de Krom MC. Primary intracranial hypotension and abnormal radionuclide cisternography: report of a case and review of the literature. Clin Neurol Neurosurg. 1991; 93:55-60.

28. Moriyama E, Ogawa T, Nishida A, et al. Quantitative analysis of radioisotope cisternography in the diagnosis of intracranial hypotension. $J$ Neurosurg. 2004;101:421-426.

29. Sencakova D, Mokri B, McClelland RL. The efficacy of epidural blood patch in spontaneous CSF leaks. Neurology. 2001;57:1921-1923.

30.Berroir S, Loisel B, Ducros A, et al. Early epidural blood patch in spontaneous intracranial hypotension. Neurology. 2004;63:1950-1951.

31.Schievink WI, Maya MM, Riedinger M. Recurrent spontaneous spinal cerebrospinal fluid leaks and intracranial hypotension: a prospective study. $J$ Neurosurg. 2003;99:840-842.

32.Aidi S, Chaunu MP, Biousse V, et al Changing pattern of headache pointing to cerebral venous thrombosis after lumbar puncture and intravenous high-dose corticosteroids. Headache 1999;39:559564.

33. Berroir S, Grabli D, Heran F, et al. Cerebral sinus venous thrombosis in two patients with spontaneous intracranial hypotension. Cerebrovasc Dis. 2004;17:912.

34.Tan K, Venketasubramanian N, Hwang CY, Lim CCT. My headache does not get better when I lie down: Spontaneous intracranial hypotension complicated by 
venous thrombosis. Headache 36.Nayak L, Abrey LE, Iwamoto FM. 2008;48:149-152. Intracranial dural metastasis. Cancer 2009 May;1947-1953

35.Tang PH, Chan YH, Chng SM, Lim CCT.

Superior sagittal sinus thrombosis: Subtle signs on neuroimaging. Ann Acad Med Singapore 2008 May;37(5):397-401.

37.Goyal M, Scharma A, Mishra NK, Gaikwad SB, Sharma MC. Imaging apparearance of parechymeningeal tuberculosis. AJR Am J Roentgenol 1997; 169: 1421-4. 